\title{
Adapting to a changing climate
}

\section{Dealing with the impacts of climate change is better than suffering their full extent - even if it's not the best possible outcome - but to what extent are we doing so?}

By way of a medical analogy, adapting to the impacts of climate change has been compared with treating the symptoms of the climate 'problem' without addressing its underlying causes. Although we can probably all agree that tackling causes is the preferable approach, in principal, the analogy is perhaps a stronger one than was originally intended because all too often potentially avoidable health problems - such as those linked to smoking or obesity - are not avoided in practice and then require treatment. Some climatic changes and their consequences are now inevitable (although we do not know exactly the what, where and when of these, we do now have a pretty good idea of the why) and so steps to adapt in order to avoid negative impacts and exploit any new opportunities seem prudent.

So far so good, but if we are having trouble controlling the growth of greenhouse gas emissions is there any reason to expect that attempts to adapt to changes in the climate and its impacts will fare any better in practice? In many ways, societies are already adapted, or adapting, to the fluctuating climatic conditions they find themselves in. Many social, economic, political and institutional factors, as well as environmental ones, determine the success with which individuals, communities and states manage their environmental risks. Researchers, governments and aid agencies, among others concerned with development and disaster risk reduction, have long grappled with problems very similar to many of the difficulties posed by climate change. Perhaps this is grounds for hope that the challenges of adaptation might be easier for society to tackle than the collective action problem of mitigation. Is there any evidence that adaptation is taking place?

Certainly there has been a notable increase in legislation dealing with adaptation to climate change at the international level, including the Cancun Adaptation Framework, the Nairobi work programme on impacts, vulnerability and adaptation to climate change and the National Adaptation Programmes of Action (NAPAs) designed to support adaptation planning in least developed countries (http://unfccc.int/ adaptation). This has been mirrored by legislation and some high-level assessment and planning in many nations including the UK and the USA, among others.

Measuring progress in terms of action on the ground can be more difficult, however, partly because adaptation can occur on so many levels and can be highly context-specific. Assessment is particularly challenging for the private sector, which - as shown in a Commentary by Swenja Surminski on page 943 - is estimated to be responsible for over $70 \%$ of global investment in new buildings and infrastructure. Consequently, the activities of private companies are pivotal in determining not only their own resilience but also the wider resilience of society to climate change. There are encouraging signs that some are taking this responsibility seriously, with several companies including well-known brands such as BT, Ericsson, Nestlé and Allianz - seeking to establish themselves as industry leaders in adapting to climate change. However, closer analysis shows that what companies mean by adaptation is rather unclear, with the term being used to refer to a range of activities from simply raising awareness at one end of the spectrum through to the development of comprehensive adaptation strategies at the other.

An important question for the private sector is the extent to which the invisible hand of the market will 'automatically' deliver adaptation. It is certainly in a company's self-interest to be resilient to shocks and to exploit opportunities, but climate change threatens to affect more than a company's direct exposure to climate risks. Vulnerability can also arise through supply of critical services (energy and transport) and the response of customers, suppliers and employees (and potentially also competitors, insurers and investors). Viewed in this way, there is a clear analogy with ecological responses to climate change, where individual species responses (such as changes in flowering dates) can lead to higher-level vulnerabilities (for example, flower-pollinator mismatches), and it seems far from clear that market incentives will foster resilience at this level.

Surminski notes a series of barriers to adaptation, including uncertainties associated with climate and for that matter socio-economic trends, tendency towards short-term planning horizons, financial costs and lack of expertise, as well as market failures and regulatory shortcomings. There is also typically a trade-off between the construction of robust systems and optimization of short-term economic growth. Some of these barriers may well be soluble given sufficient time and resources, but on close inspection adaptation is a surprisingly slippery concept and measuring progress seems to be an inherently difficult task.

In another Commentary in this issue (page 945), Diane Horn and Michael McShane take a more focused look at developments in the UK flood insurance market that are designed to cope with increasing financial losses from flooding. Insurance is a key risk transfer mechanism used to help individuals and organizations cope with loss. It also has the potential to discourage inappropriate development and incentivise investment in flood resilience. So will this new scheme - Flood Re, an industry-run, not-for-profit insurance fund; http://go.nature.com/IP8vK6 - deliver a mechanism for climate adaptation?

Flood Re is designed to support the 500,000 residential properties in locations where flood insurance is unavailable or unaffordable. Unfortunately, Horn and McShane find the likelihood that the scheme will act as a primary mechanism for adaptation rather low, as the current incarnation offers no incentive to encourage the development of flood resilience, and leaves open the potential for a crisis over who is liable for excess flood damages. They suggest that building regulations, land-use planning and water management will be required to move the situation towards one where the UK is adapting to enhanced flood risk with Flood Re at best playing a supporting role.

If we are going to rely increasingly on adaptation measures to cope with climate change it is clear that there is much work to do to ensure that progress is made and can be measured on the ground. Not least in the crucial, but frequently enigmatic private sector, where Surminski finds that at present we "do not know how most companies consider climate risk, let alone whether they take any action". 